\title{
PSO-SVM applied to SWASV studies for accurate detection of Cd(II) based on disposable electrode
}

\author{
Zhao Guo ${ }^{1,2}$, Wang Hui ${ }^{1,2}$, Yin Yuan ${ }^{1,2}$, Liu Gang ${ }^{1,2^{*}}$ \\ (1. Key Laboratory of Modern Precision Agriculture System Integration Research, Ministry of Education of China, China Agricultural \\ University, Beijing 100083, China; 2. Key Laboratory of Agricultural Information Acquisition Technology, Ministry of Agricultural of \\ China, China Agricultural University, Beijing 100083, China)
}

\begin{abstract}
Square wave anodic stripping voltammetry (SWASV) is an effective method for the detection of Cd(II), but the presence of $\mathrm{Pb}(\mathrm{II})$ usually has some potential and negative interference on the SWASV detection of $\mathrm{Cd}(\mathrm{II})$. In this paper, a novel method was proposed to predict the concentration of $\mathrm{Cd}(\mathrm{II})$ in the presence of $\mathrm{Pb}(\mathrm{II})$ based on the combination of chemically modified electrode (CME), machine learning algorithms (MLA) and SWASV. A Bi film/ionic liquid/screenprinted electrode $(\mathrm{Bi} / \mathrm{IL} / \mathrm{SPE})$ was prepared and used for the sensitive detection of trace $\mathrm{Cd}(\mathrm{II})$. The parameters affecting the stripping currents were investigated and optimized. The morphologies and electrochemical properties of the modified electrode were characterized by scanning electron microscopy (SEM) and SWASV. The measured SWASV spectrograms obtained at different concentrations were used to build the mathematical models for the prediction of $\mathrm{Cd}(\mathrm{II})$, which taking the combined effect of $\mathrm{Cd}(\mathrm{II})$ and $\mathrm{Pb}(\mathrm{II})$ into consideration on the SWASV detection of $\mathrm{Cd}(\mathrm{II})$, and to establish a nonlinear relationship between the stripping currents of $\mathrm{Pb}(\mathrm{II})$ and $\mathrm{Cd}(\mathrm{II})$ and the concentration of $\mathrm{Cd}(\mathrm{II})$. The proposed mathematical models rely on an improved particle swarm optimization-support vector machine (PSO-SVM) to assess the concentration of $\mathrm{Cd}(\mathrm{II})$ in the presence of $\mathrm{Pb}(\mathrm{II})$ in a wide range of concentrations. The experimental results suggest that this method is suitable to fulfill the goal of $\mathrm{Cd}(\mathrm{II})$ detection in the presence of $\mathrm{Pb}(\mathrm{II})$ (correlation coefficient, mean absolute error and root mean square error were $0.998,1.63$ and 1.68 , respectively). Finally, the proposed method was applied to predict the trace Cd(II) in soil samples with satisfactory results.
\end{abstract}

Keywords: square wave anodic stripping voltammetry (SWASV), particle swarm, support vector machine, screen-printed electrode, heavy metals, Cd detection, soil pollution

DOI: $10.25165 /$ j.ijabe.20171005.2863

Citation: Zhao G, Wang H, Yin Y, Liu G. PSO-SVM applied to SWASV studies for accurate detection of Cd(II) based on disposable electrode. Int J Agric \& Biol Eng, 2017; 10(5): 251-261.

\section{Introduction}

As one of the most toxic heavy metals in the

\section{Received date: 2016-09-23 Accepted date: 2017-06-23}

Biographies: Zhao Guo, $\mathrm{PhD}$ candidate, research interests: Agricultural Electrification and Automation, Email: 1252624780@ qq.com; Wang Hui, PhD candidate, research interests: agricultural electrification and automation, Email: wanghuilunwem@gmail. com; Yin Yuan, Master, research interests: agricultural electrification and automation, Email: 1144729812@qq.com.

*Corresponding author: Liu Gang, Professor, research interests: agricultural electrification and automation, Key Laboratory of Modern Precision Agriculture System Integration Research, Ministry of Education, China Agriculture University, Beijing 100083, China. Tel: +86-10-62736741, Email: pac@cau.edu.cn. environment, cadmium poses a great threat to human health due to its non-biodegradability and persistence ${ }^{[1]}$. The main route of exposure to cadmium for humans is through plants by way of soil, directly or indirectly entering the human body ${ }^{[2]}$. Thus, developing a rapid, simple, accurate, and reliable method for the on-site detection of cadmium in soil is very desirable $\mathrm{e}^{[3-5]}$.

Various techniques including inductively coupled plasma optical emission spectrometry $(\mathrm{ICP}-\mathrm{OES})^{[6]}$, $\mathrm{UV}-\mathrm{Vis}$ spectroscopy ${ }^{[7]}$, atomic fluorescence spectroscopy ${ }^{[8]}$, surface-enhanced Raman spectrometry $(\mathrm{SERS})^{[9]}$, inductively coupled plasma mass spectrometry $(\mathrm{ICP}-\mathrm{MS})^{[10]}$, atomic absorption spectroscopy $(\mathrm{AAS})^{[11]}$, 
ion chromatography ${ }^{[12]}$ and colorimetric analysis ${ }^{[13]}$ have been used for heavy metals analysis. However, these methods have several drawbacks such as time-consuming analysis, high cost, demanding for complex instrumentation and unsuitability for on-site analysis. Among these methods, anodic stripping voltammetry (ASV) is one of the superior electrochemical methods due to its ease of operation, low cost, reliability, inexpensive instrumentation, quick analysis and fast response $\mathrm{e}^{[14,15]}$. However, the presence of other heavy metal ions (HMs) may influence the stripping responses of the target $\mathrm{HMs}^{[4,16-18]}$, which would decrease the detection precision of the direct calibration model.

Chemically modified electrodes (CMEs) represent one of the active research areas in the ASV detection of heavy metals, which can effectively improve the electrochemical properties of electrodes ${ }^{[19-21]}$. As a result of the increasing demand for industrial, environmental and food analyses, a variety of screen-printed electrodes (SPEs) have been used for on-site monitoring and point-of-care testing due to their mass production, simple fabrication and low $\operatorname{cost}^{[22-25]}$. However, the use of nonconductive binders or insulating polymers in the preparation of SPEs may reduce the electronic transmission capability and shelter carbon particles that have electrochemical activity, which will result in the poor kinetics of the heterogeneous reaction $^{[26]}$. Ionic liquids (ILs) have many excellent properties such as a good physical and chemical stability, a wide potential window and a high ionic conductivity. The capabilities of ILs for being combined with carbon materials to form conductive composites make them very attractive for electrode modification. In the past decades, many papers have reported the use of CMEs in the ASV detection of $\mathrm{Cd}(\mathrm{II})^{[22,27-30]}$. Some of these studies considered the interference of $\mathrm{Pb}(\mathrm{II})$ in the SWASV detection of $\mathrm{Cd}(\mathrm{II})$; however, most of the reported works only considered the effect of $\mathrm{Pb}(\mathrm{II})$ on the SWASV detection of $\mathrm{Cd}(\mathrm{II})$ at a certain concentration, instead of various $\mathrm{Pb}$ (II) concentrations.

Machine learning method is a subfield of computer science and it is classified as an artificial intelligence method. It can be used in several domains and the advantage of this method is that a model can solve problems which are impossible to be represented by explicit algorithms ${ }^{[31]}$. The machine learning models find relations between inputs and outputs even if the representation is impossible; this characteristic allows the use of machine learning models in the case of forecasting problems as described in the previous report ${ }^{[32]}$. Support vector machines (SVMs) are a type of novel machine learning method based on statistical learning theory, which is a new powerful tool for identification and prediction in nonlinear systems ${ }^{[33]}$. Particle swarm optimization (PSO) is generally used with SVM for feature selection and extraction ${ }^{[34,35]}$, parameter optimization of $\mathrm{SVM}^{[36-40]}$ and multi-class classification in $\mathrm{SVM}^{[41]}$. In this paper, a PSO algorithm was used for the parameter optimization of SVM from training data, i.e., PSO-SVM. Moreover, an improved PSO-SVM model was used to discover, process, and interpret the nonlinear relationships between the stripping peak currents of $\mathrm{Cd}(\mathrm{II})$ and $\mathrm{Pb}$ (II) and the concentrations of $\mathrm{Cd}(\mathrm{II})$ and to create a simple and manageable model for $\mathrm{Cd}(\mathrm{II})$ detection. To the best of our knowledge, very few studies have investigated the combination of SWASV and improved PSO-SVM to detect Cd(II) in the presence of $\mathrm{Pb}(\mathrm{II})$.

To sum up, in this study, a Bi/IL/SPE was prepared, with N-octylpyridinum hexafluorophosphate (OPFP) as a modifier and binder. Furthermore, an easy but effective method based on the combination of SWASV and improved PSO-SVM was proposed for the optimization of a $\mathrm{Bi} / \mathrm{IL} / \mathrm{SPE}$ sensor to realize the accurate detection of $\mathrm{Cd}(\mathrm{II})$ in the presence of $\mathrm{Pb}(\mathrm{II})$. The effects of different concentrations of $\mathrm{Pb}$ (II) on the stripping voltammetric responses of $\mathrm{Cd}(\mathrm{II})$ was also studied to analyze the relationship between the stripping peak currents of $\mathrm{Pb}(\mathrm{II})$ and $\mathrm{Cd}(\mathrm{II})$ and the concentrations of $\mathrm{Cd}(\mathrm{II})$. Consequently, the combination of SWASV and PSO-SVM can be viewed as a source of many potential methods for detecting and quantifying many different types of HMs in various natural samples.

\section{Materials and methods}

\subsection{Reagents and instrumentation}

The OPFP IL was purchased from Shanghai Chengjie 
Co., Ltd. (Shanghai, China). Graphite powder (spectral purity, size $<20 \mu \mathrm{m}$ ) and cellulose acetate (CA) were obtained from Sinopharm Chemical Reagent Co., Ltd. (Shanghai, China). Stock solutions of $\mathrm{Bi}(\mathrm{III}), \mathrm{Pb}$ (II) and $\mathrm{Cd}(\mathrm{II})(1000 \mathrm{mg} / \mathrm{L})$ were purchased from the National Standard Reference Materials Center of China and diluted as required. Acetate buffer $(0.1 \mathrm{M})$ served as the supporting electrolyte for the detection of $\mathrm{Cd}(\mathrm{II})$. All other chemicals were of analytical grade and used without further purification. Millipore-Q (18.2 M $\Omega$ ) water was used for all experiments.

SEM analysis was carried out on a JSM-6701F field emission scanning electron microscope produced by JEOL Ltd. (Japan). SWASV was performed using a CHI660D electrochemical workstation (Shanghai $\mathrm{CH}$ Instruments, China). Screen-printed 3-electrode systems, with carbon working electrodes (diameter of $3 \mathrm{~mm}$ ), carbon counter electrodes and $\mathrm{Ag} / \mathrm{AgCl}$ reference electrodes, were obtained from the Shanghai Mumei Electronic Technology Co., Ltd. (Shanghai, China). All electrochemical measurements were carried out in a $25 \mathrm{~mL}$ cell. A magnetic stirrer was used to stir the test solutions during the deposition steps.

\subsection{Electrode preparation and modification}

Briefly, $0.1 \mathrm{~g}$ of CA, $1.0 \mathrm{~g}$ of OPFP and $4.0 \mathrm{~g}$ of the graphite powder were added into a mixed solvent containing $5 \mathrm{~mL}$ of cyclohexanone and $5 \mathrm{~mL}$ of acetone. Then, a viscous ink was produced by sonicating the obtained composite for $12 \mathrm{~h}$. Next, $7 \mu \mathrm{L}$ of the viscous ink was cast onto the SPE surface and left to dry at room temperature. Finally, the electrode surface was smoothed by using a piece of weighing paper to obtain a new uniform surface.

\subsection{Cd(II) detection by SWASV in the presence of $\mathrm{Pb}(\mathrm{II})$}

The SWASV detection of Cd(II) was carried out in $0.1 \mathrm{M}$ acetate buffer solutions ( $\mathrm{pH}$ 5.0) in the presence of $600 \mu \mathrm{g} / \mathrm{L} \mathrm{Bi}(\mathrm{III})$, which formed a bismuth film by the in-situ deposition. The measurements on the stripping currents of these two HMs (Cd(II) and $\mathrm{Pb}$ (II)) in their mixtures were performed in a wide range of concentrations which ranged from $1 \mu \mathrm{g} / \mathrm{L}$ to $110 \mu \mathrm{g} / \mathrm{L}$. A deposition potential of $-1.2 \mathrm{~V}$ was applied to the working electrode for $150 \mathrm{~s}$ during the deposition steps under stirring. After a $10 \mathrm{~s}$ equilibration period, the SWASV potential scan was conducted from $-1.2 \mathrm{~V}$ to $0.2 \mathrm{~V}$; the solution was not stirred during these two steps. The potential step, square-wave amplitude and frequency were $5 \mathrm{mV}, 25 \mathrm{mV}$ and $25 \mathrm{~Hz}$, respectively. Before the next detection, the modified electrode was activated for $150 \mathrm{~s}$ at $0.31 \mathrm{~V}$ in a pH 5.0 acetate buffer under stirring to remove the residual metals and the bismuth film on the surface of the working electrode. All of the experiments were performed at room temperature.

\subsection{SVM optimized by the particle swarm algorithm}

SVM is a robust machine learning technique widely used in establishing both linear and non-linear models ${ }^{[42]}$. The performance of SVMs in classification and regression depends on several factors, including the kernel function type and its corresponding parameters, the capacity parameter $(C)$ and the kernel function parameter $(\gamma)$. First, the kernel function should be identified to determine the sample distribution in the mapping space. The radial basis function (RBF) was used in this study because of its good general performance, and only a few parameters needing adjusted ${ }^{[43]}$. The parameter $C$ controls the trade-off between maximizing the margin and minimizing the training error. The $\gamma$ of the kernel function greatly affects the number of support vectors (SVs), which is closely related with the prediction performance of the SVM and the training time. Too many SVs can result in overfitting and increase the training time. In addition, $\gamma$ controls the amplitude of the RBF function and hence controls the generalization ability of the SVM. PSO is an efficient evolutionary computational technique that simulates the behavior of birds searching for food and has been widely used in function optimization ${ }^{[44-46]}$. Coupled with the PSO algorithm, SVM was developed as a parameter-free modeling technique that enables the construction of a rational and self-adaptive prediction model according to the performance of the total model. In this paper, The PSO-SVM model was developed to predict the non-linear relationship between the $\mathrm{Cd}(\mathrm{II})$ concentration and the stripping peak currents of $\mathrm{Pb}(\mathrm{II})$ and $\mathrm{Cd}(\mathrm{II})$. The inputs of the model were the stripping peak currents of $\mathrm{Pb}(\mathrm{II})$ 
and $\mathrm{Cd}(\mathrm{II})$, and the concentration of $\mathrm{Cd}(\mathrm{II})$ was the output of the model. The accurate detection of $\mathrm{Cd}$ (II) in the presence of $\mathrm{Pb}(\mathrm{II})$ has been attempted based on the combination of the improved PSO-SVM and SWASV with a $\mathrm{Bi} / \mathrm{IL} / \mathrm{SPE}$. The prediction performance of the improved PSO-SVM was evaluated by mean absolute error (MAE), root mean square error (RMSE) and correlation coefficient $\left(R^{2}\right)^{[32,47]}$. All the PSO-SVMrelated calculations and simulation have been carried out by utilizing MATLAB R2012b (The Mathworks, Inc., USA).

\subsection{Soil sample preparation}

Soil samples were obtained from farmland in China. The soil samples were pretreated to obtain soil extract solutions according to the methods described in previously published papers ${ }^{[17,48]}$. Briefly, the soil samples were placed in an oven to dry for $2 \mathrm{~h}$. The soil samples were then pulverized on a portable soil crusher and subsequently sieved through a $200 \mathrm{~mm}$ sieve. The soil samples ( $1 \mathrm{~g})$ were placed in an extraction bottle and extracted with $40 \mathrm{~mL}$ of $0.11 \mathrm{M}$ acetic acid. The mixed samples were put into an end-over-end shaker for shaking $16 \mathrm{~h}$ at room temperature. The mixed samples were subjected to centrifugal sedimentation experiments for phase separation. The extracts of HMs in aqueous phase were then filtered by a membrane to remove micro-impurities from the solutions. According to the experimental results of "optimization of experimental conditions", the maximum stripping peak current appeared at $\mathrm{pH} 5.0$ on the $\mathrm{Bi} / \mathrm{IL} / \mathrm{SPE}$ based on SWASV (cf. section 3.1). In order to improve the sensitivity of the SWASV detection of Cd(II) with the Bi/IL/SPE, the $\mathrm{pH}$ of extracts solution was adjusted to 5.0 by adding $0.11 \mathrm{M} \mathrm{NaOH}$.

\section{Results and discussion}

\subsection{Optimization of experimental conditions}

To improve the sensitivity for the SWASV detection of $\mathrm{Cd}(\mathrm{II})$ in the presence of $\mathrm{Pb}(\mathrm{II})$ with the $\mathrm{Bi} / \mathrm{IL} / \mathrm{SPE}$, the different SWASV parameters were optimized, including the $\mathrm{pH}$ of the supporting electrolyte, Bi(III) concentration, deposition potential and the deposition time.

The effect of $\mathrm{pH}$ in the range of 3.5-6 on the stripping responses of the target HMs was investigated, as shown in Figure 1a. The maximum peak current appeared at $\mathrm{pH}$ 5.0; therefore, the following experiments were conducted at $\mathrm{pH}$ 5.0. Figure $1 \mathrm{~b}$ shows the effect of the $\mathrm{Bi}(\mathrm{III})$ concentration on the peak currents of $\mathrm{Cd}(\mathrm{II})$. The peak currents increased with an increasing $\mathrm{Bi}(\mathrm{III})$ concentration from $100 \mu \mathrm{g} / \mathrm{L}$ to $600 \mu \mathrm{g} / \mathrm{L}$ and then decreased when the $\mathrm{Bi}(\mathrm{III})$ concentration exceeded $600 \mu \mathrm{g} / \mathrm{L}$. Thus $600 \mu \mathrm{g} / \mathrm{L}$ was chosen as the optimal Bi(III) concentration. The effect of the deposition potential on the peak currents of $\mathrm{Cd}(\mathrm{II})$ over a potential range of $-0.8 \mathrm{~V}$ to $-1.6 \mathrm{~V}$ after accumulation for $150 \mathrm{~s}$ was investigated, as shown in Figure 1c. When the deposition potential was in the range of $-0.8 \mathrm{~V}$ to $-1.2 \mathrm{~V}$, the peak current increased with the increase of the deposition potential, which may be due to the further reduction of cadmium ions, but when the deposition potential continued to increase on the basis of $-1.2 \mathrm{~V}$, the peak current would gradually decrease, which may be due to the occurrence of hydrogen evolution reaction. For further determinations, the accumulation potential of $-1.2 \mathrm{~V}$ was chosen for HMs preconcentration. As can be seen in Figure 1d, the peak currents increase with the increase of deposition time. However, as the deposition time exceeded $150 \mathrm{~s}$, the peak currents versus time began to increase slowly. In the present study, considering both the sensitivity and efficiency of the $\mathrm{Cd}(\mathrm{II})$ detection , a deposition period of $150 \mathrm{~s}$ was used in subsequent experiments.

\subsection{Effects of $\mathrm{Pb}(\mathrm{II})$ on the SWASV detection of Cd(II) based on Bi/IL/SPE}

The surface morphologies of the bare SPE and IL/SPE were characterized by SEM. An SEM image of the bare SPE surface was presented in Figure 2a, showing the disordered distribution of graphite flakes, which undoubtedly affected the conductivity of electrode ${ }^{[49]}$. Figure $2 b$ illustrates the surface image of IL/SPE, in which a compact and wrinkled paper-like structure can be observed, indicating the good adherence of OPFP with graphite particle. The IL and carbon particles firmly bind together and form a stable solid composition, which not only improves the mechanical stability but also increases the electron transfer rate of the electrode. 


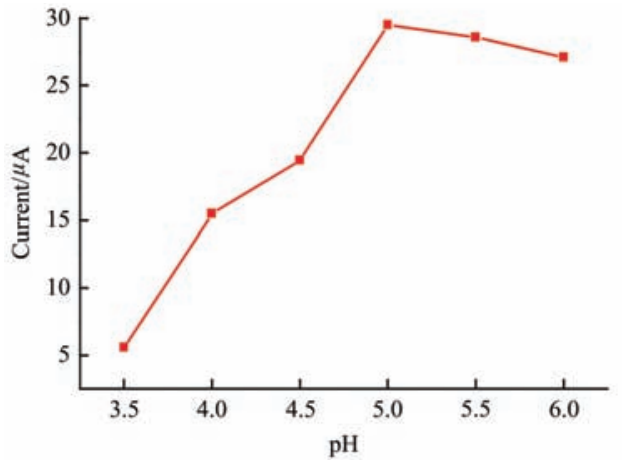

a. $\mathrm{pH}$

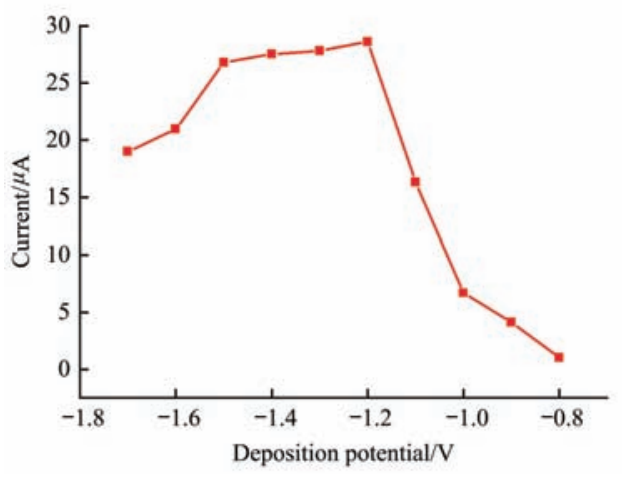

c. Deposition potential

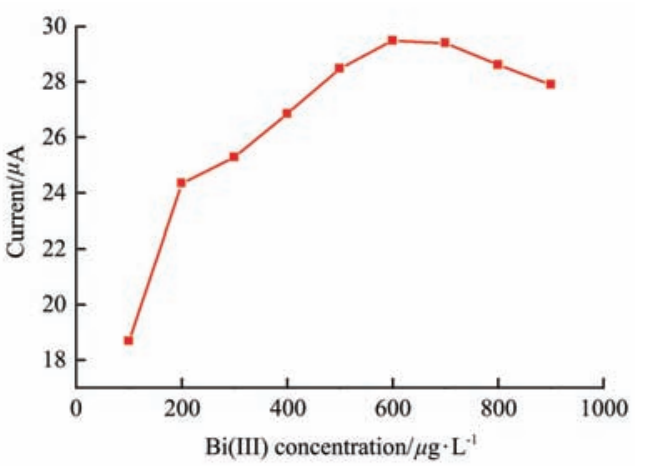

b. $\mathrm{Bi}(\mathrm{III})$

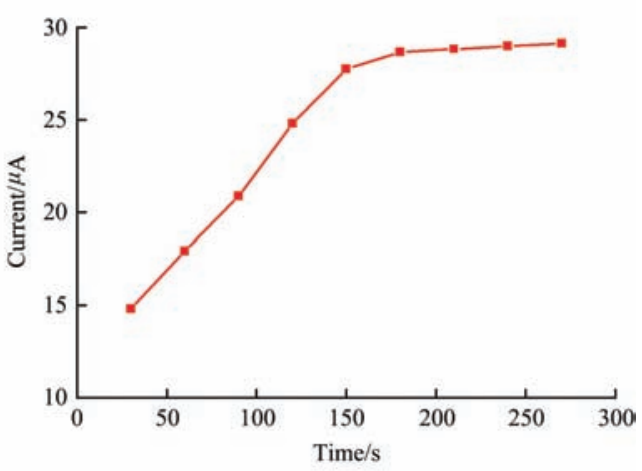

d. Deposition time

Figure 1 Effects of $\mathrm{pH}, \mathrm{Bi}(\mathrm{III})$ concentration, deposition potential and deposition time on the stripping peak current of $30 \mu \mathrm{g} / \mathrm{L} \mathrm{Cd}(\mathrm{II})$ in the presence of $30 \mu \mathrm{g} / \mathrm{L} \mathrm{Pb}(\mathrm{II})$

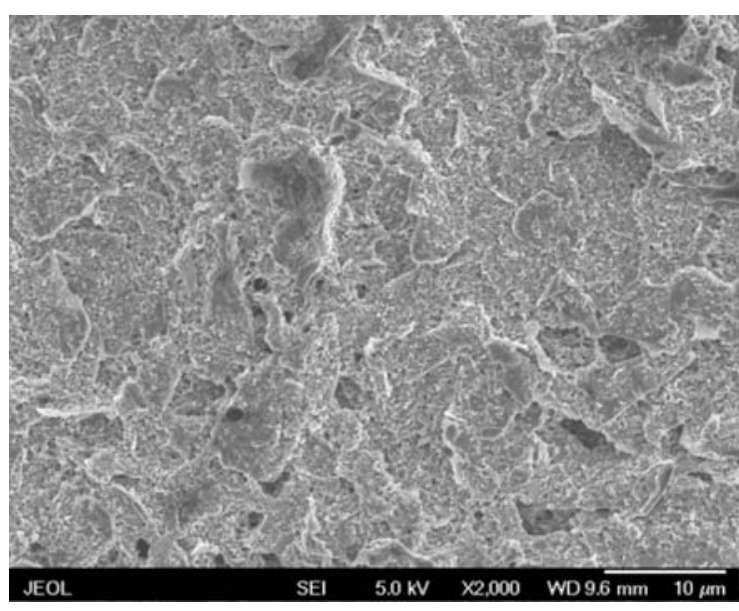

a. Bare SPE

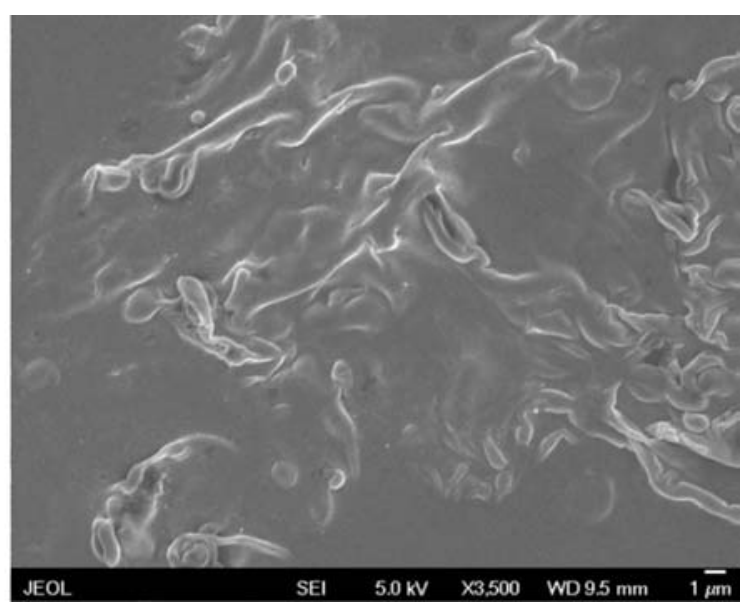

b. IL/SPE

Figure 2 SEM images of surface morphologies of bare SPE, IL/SPE

Figure 3 compares the peak currents of $40 \mu \mathrm{g} / \mathrm{L}$ Cd(II) and $\mathrm{Pb}$ (II) on the different modified electrodes. As it is shown, the IL/SPE (curve b) exhibites higher stripping peak currents toward both HMs as compared with bare SPE (curve a), possibly attributed to that the high conductive IL enhanced the electron transfer ability and improved the preconcentration efficiency of HMs on the electrode surface ${ }^{[50]}$. The highest striping peaks on the detection of $\mathrm{Cd}(\mathrm{II})$ and $\mathrm{Pb}$ (II) was observed for Bi/IL/SPE (curve c). Such improvement can be attributed to the fact that Bi can form alloys with HMs, which reduces HMs more easily ${ }^{[51]}$.

Although the higher stripping voltammetry sensitivity of $\mathrm{Cd}(\mathrm{II})$ could be obtained using $\mathrm{Bi} / \mathrm{IL} / \mathrm{SPE}$ as compared with bare SPE in the presence of $\mathrm{Pb}$ (II). Interactive interference in the determination of $\mathrm{HMs}$, as a common problem, could reduce the detection accuracy of target HMs (in this case, $\mathrm{Cd}(\mathrm{II})$ ). In order to realize the accurate detection of $\mathrm{Cd}(\mathrm{II})$ in the presence of $\mathrm{Pb}(\mathrm{II})$, additional studies were performed on the stripping processes of these two metal ions in their mixtures to investigate the effects of different concentrations of 
$\mathrm{Pb}(\mathrm{II})$ on the SWASV detection of $\mathrm{Cd}(\mathrm{II})$ based on $\mathrm{Bi} / \mathrm{IL} / \mathrm{SPE}$.

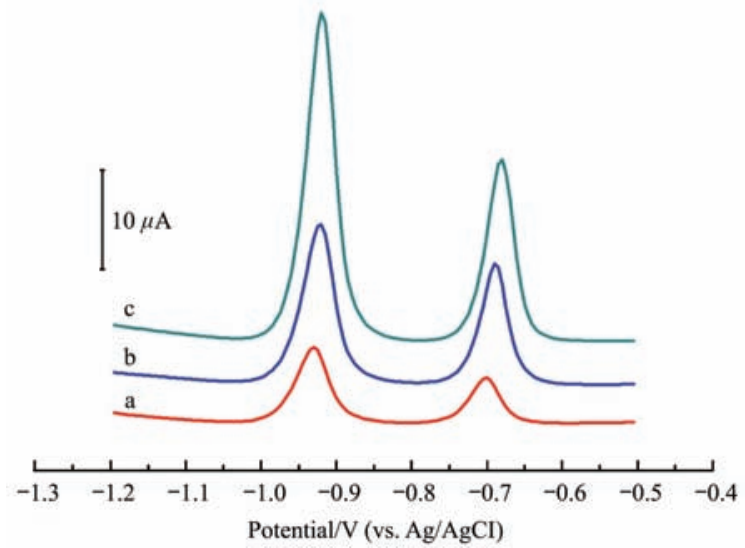

Figure 3 Stripping voltammetric responses of $40 \mu \mathrm{g} / \mathrm{L} \mathrm{Cd(II)} \mathrm{and}$ $\mathrm{Pb}$ (II) in $0.1 \mathrm{M}$ acetate buffer solution (pH 5.0) on the (a) SPE,

(b) IL/SPE, (c) Bi/IL/SPE. Deposition time: $150 \mathrm{~s}$.

Deposition potential: $-1.2 \mathrm{~V}$. Concentration of Bi(III): $600 \mu \mathrm{g} / \mathrm{L}$
The SWASV voltammograms containing the stripping currents of $\mathrm{Cd}(\mathrm{II})$ and $\mathrm{Pb}$ (II) in different concentrations were recorded under the optimized conditions, as shown in Figure 4. The SWASV detection was carried out by changing the concentration of one HM while holding the concentration of the other HM constant. As observed from Figure 4, the linearity of the calibration equations of $\mathrm{Cd}(\mathrm{II})$ detection in the presence of different concentrations of $\mathrm{Pb}(\mathrm{II})$ were practically unaffected by the increasing $\mathrm{Pb}(\mathrm{II})$ concentration, but the calibration equation itself was obviously affected by the different concentrations of $\mathrm{Pb}(\mathrm{II})$, which indicates that no calibration equation is universally applicable for the detection of $\mathrm{Cd}(\mathrm{II})$ due to the existence of different concentrations of $\mathrm{Pb}(\mathrm{II})$ in the real samples.

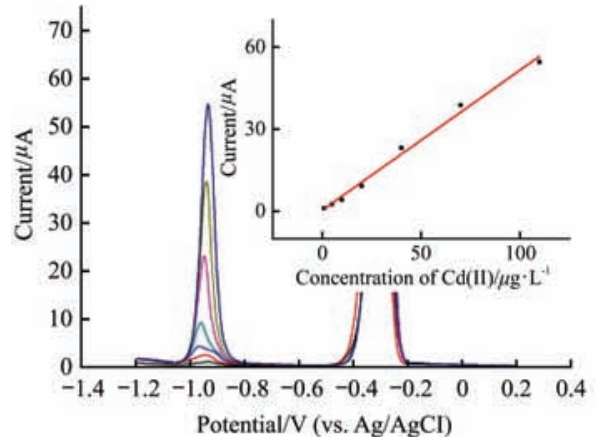

a. $0 \mu \mathrm{g} / \mathrm{L}$

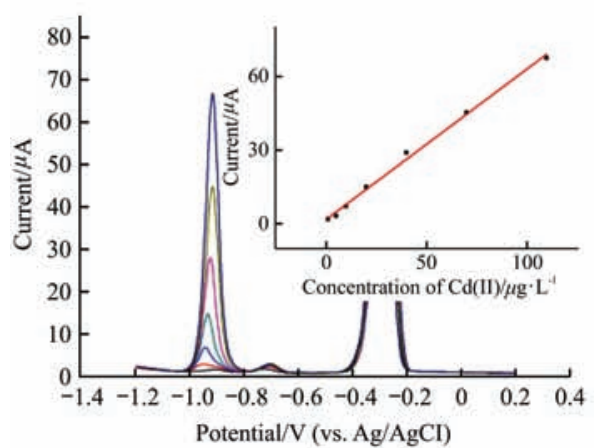

d. $10 \mu \mathrm{g} / \mathrm{L}$

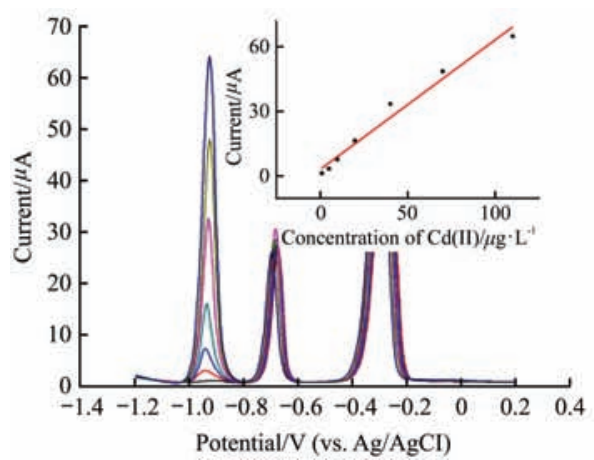

g. $70 \mu \mathrm{g} / \mathrm{L}$

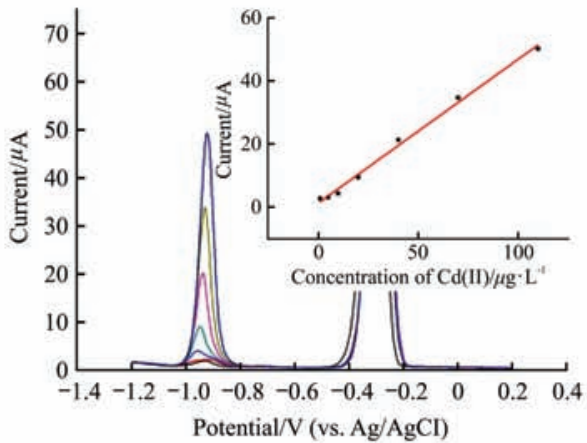

b. $1 \mu \mathrm{g} / \mathrm{L}$

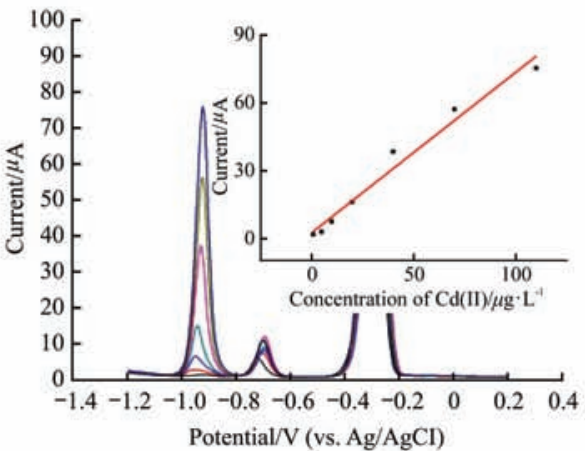

e. $20 \mu \mathrm{g} / \mathrm{L}$

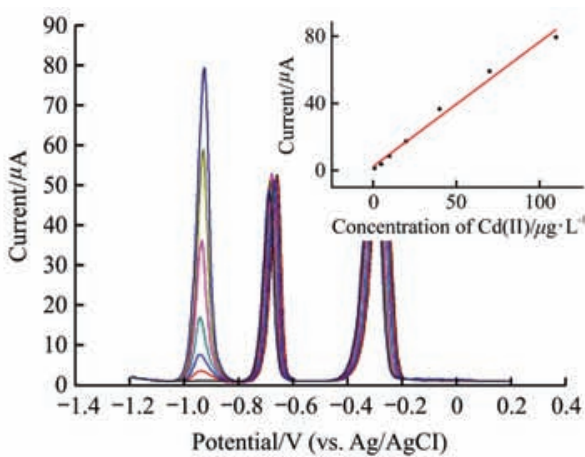

h. $110 \mu \mathrm{g} / \mathrm{L}$

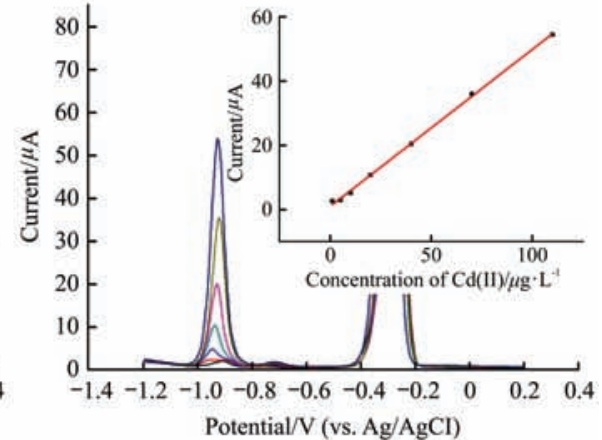

c. $5 \mu \mathrm{g} / \mathrm{L}$

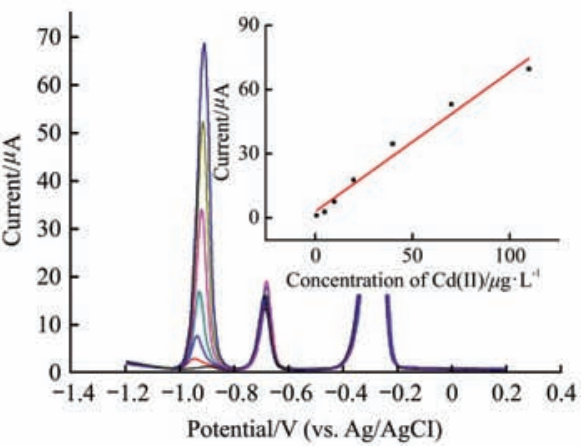

f. $40 \mu \mathrm{g} / \mathrm{L}$

Figure 4 Voltammograms for $\mathrm{Cd}(\mathrm{II})$ ranging from $1.0 \mu \mathrm{g} / \mathrm{L}$ to $110 \mu \mathrm{g} / \mathrm{L}$ in different concentrations of $\mathrm{Pb}$ (II) ranging from 0 to $110 \mu \mathrm{g} / \mathrm{L}$ (Deposition time: $150 \mathrm{~s}$. Deposition potential: $-1.2 \mathrm{~V}$. Concentration of Bi(III): $600 \mu \mathrm{g} / \mathrm{L}$ ) 
The obtained results in Figure 5a show that the calibration curve of $\mathrm{Cd}(\mathrm{II})$ significantly affected by different concentrations of $\mathrm{Pb}(\mathrm{II})$ as compared with the absence of $\mathrm{Pb}$ (II). Figure $5 \mathrm{~b}$ demonstrates the effect of different concentrations of $\mathrm{Pb}(\mathrm{II})$ on the stripping response of $\mathrm{Cd}(\mathrm{II})$. As observed from Figure $5 \mathrm{~b}$, the presence of $20 \mu \mathrm{g} / \mathrm{L} \mathrm{Cd}(\mathrm{II})$ has a significant influence on the stripping response of $\mathrm{Cd}(\mathrm{II})$ in the range of 1.0 to $70 \mu \mathrm{g} / \mathrm{L}$. When the concentration of $\mathrm{Pb}$ (II) was more than $70 \mu \mathrm{g} / \mathrm{L}$, the interference of $\mathrm{Pb}(\mathrm{II})$ on the stripping

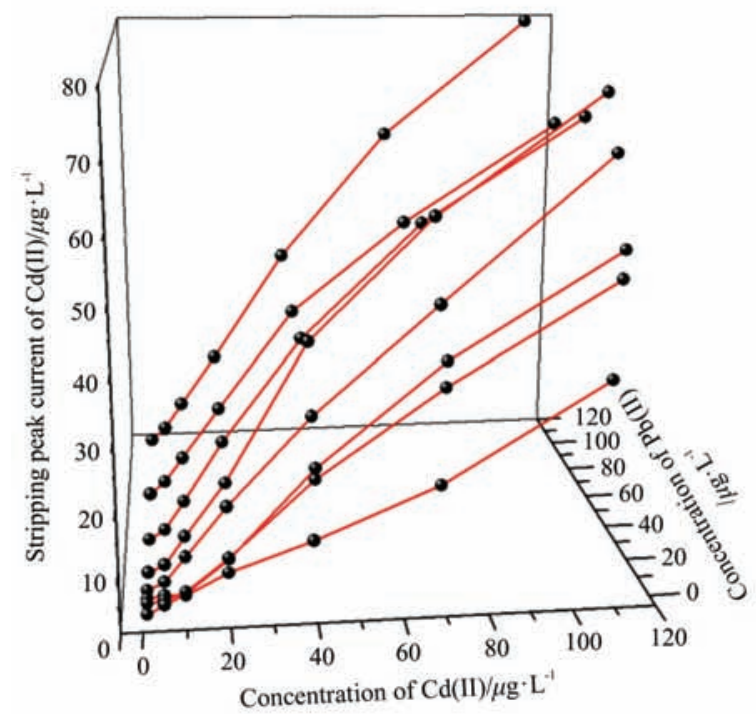

a response of $\mathrm{Cd}(\mathrm{II})$ still existed and had a more significant effect on the higher concentration of $\mathrm{Cd}(\mathrm{II})$. The influence of $\mathrm{Pb}(\mathrm{II})$ on the stripping responses of $\mathrm{Cd}(\mathrm{II})$ may be due to the close similarity in electrochemical behavior of these two HMs. Furthermore, the presence of $\mathrm{Cd}$ (II) may have a negative effect on both the reduction of $\mathrm{Cd}(\mathrm{II})$ on the surface of the electrode during the deposition step and the stripping of $\mathrm{Cd}$ during the stripping step, because $\mathrm{Cd}$ can form multicomponent alloys with $\mathrm{Pb}$ and $\mathrm{Bi}$.

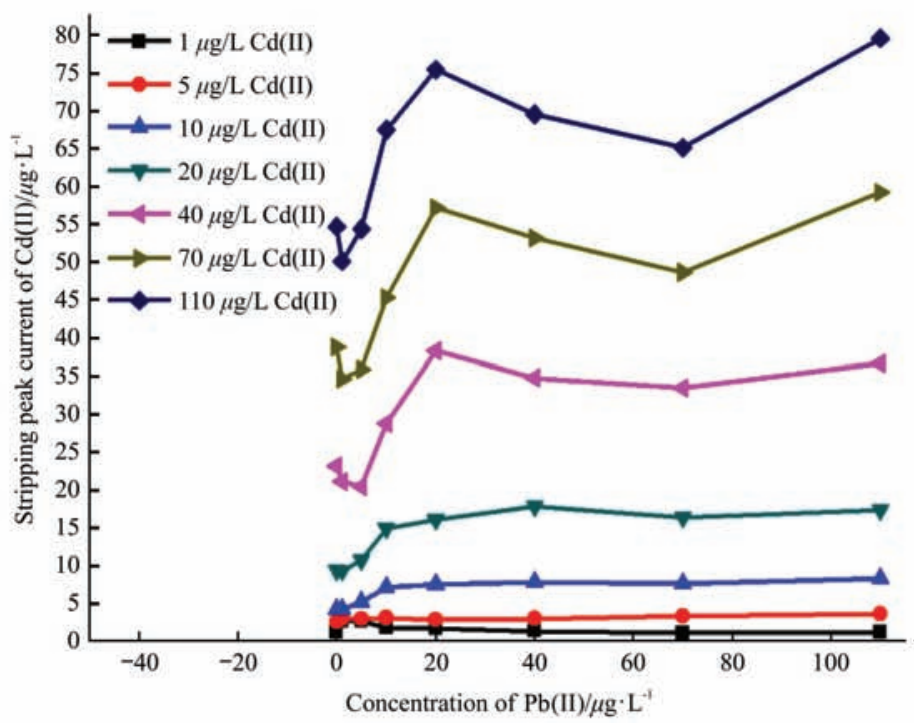

b

Figure 5 Effects of different concentrations of $\mathrm{Pb}$ (II) on the fitting curve (a) and stripping peak currents of $\mathrm{Cd}$ (II)

The interference of $\mathrm{Pb}(\mathrm{II})$ on the stripping responses of $\mathrm{Cd}(\mathrm{II})$ would lead to the changes of the calibration equations as compared with the absence of $\mathrm{Pb}(\mathrm{II})$, and thereby reduce the prediction accuracy of $\mathrm{Cd}(\mathrm{II})$ based on SWASV. These changes of calibration equations are listed in Table 1 which presents the calibration equations of $\mathrm{Cd}(\mathrm{II})$ and the $A d j$. R-Square $\left(R^{2}\right)$ in the presence of different concentrations of $\mathrm{Pb}(\mathrm{II})$ as compared with the absence of $\mathrm{Pb}(\mathrm{II})$. From Table 1, it can be seen that the calibration equations of $\mathrm{Cd}(\mathrm{II})$, including the slope and intercept, were affected by the different concentrations of $\mathrm{Pb}(\mathrm{II})$ as compared with the calibration equation of $\mathrm{Cd}(\mathrm{II})$ in the absence of $\mathrm{Pb}$ (II). Therefore, the presence of $\mathrm{Pb}$ (II) will lead to low detection precision of $\mathrm{Cd}$ (II) when using the direct calibration model based on SWASV. The presence of different concentrations of $\mathrm{Pb}$ (II) leads to a change in the calibration model, which reduced the detection accuracy of $\mathrm{Cd}(\mathrm{II})$ to different degrees.
Table 1 Linear calibration equations of $\mathrm{Cd}(\mathrm{II})$ in the presence of different concentrations of $\mathrm{Pb}(\mathrm{II})$

\begin{tabular}{ccc}
\hline $\mathrm{Pb}(\mathrm{II})$ concentration $/ \mu \mathrm{g} \cdot \mathrm{L}^{-1}$ & Linear calibration equation $(\mathrm{Cd}(\mathrm{II}))$ & $R^{2}$ \\
\hline 0 & $Y=0.512 X+0.396$ & 0.991 \\
1 & $Y=0.456 X+1.17$ & 0.987 \\
5 & $Y=0.487 X+1.06$ & 0.999 \\
10 & $Y=0.611 X+1.72$ & 0.995 \\
20 & $Y=0.713 X+2.34$ & 0.971 \\
40 & $Y=0.651 X+2.96$ & 0.971 \\
70 & $Y=0.605 X+2.99$ & 0.971 \\
110 & $Y=0.746 X+2.14$ & 0.983 \\
\hline
\end{tabular}

\subsection{Proposed PSO-SVM model for the detection of} Cd(II)

\subsubsection{Model training and optimization}

SVM was applied to build a non-linear model for the prediction of $\mathrm{Cd}(\mathrm{II})$ in the presence of $\mathrm{Pb}$ (II), with the stripping peak currents of $\mathrm{Pb}$ (II) and $\mathrm{Cd}(\mathrm{II})$ as input variables and the concentration of $\mathrm{Cd}(\mathrm{II})$ as an output variable. SVM training is an essential step to ensure the prediction accuracy of the model. This step entails the 
utilization of a training dataset to train the model. In addition, the testing dataset was used to verify the prediction precision of the proposed SVM model. In this investigation, a searching program named "particle swarm optimization algorithm" was used in the training step to determine the optimized parameter combination of $C$ and $\gamma$ while preventing the over-fitting of the training dataset. Finally, $C$ and $\gamma$ were fixed at 64.6741 and 0.38582 , respectively.

3.3.2 Establishment and validation of the improved

\section{PSO-SVM model}

Forty sets of experimental data (training dataset) were used to train the PSO-SVM model using the optimized parameter combination above, and 9 sets of experimental data were used as the testing dataset. The fitness and prediction accuracy of the proposed PSO-SVM model was evaluated by the MAE, RMSE and correlation coefficient $^{[32,47]}$. The statistical analysis results show that the prediction accuracy of the proposed model was

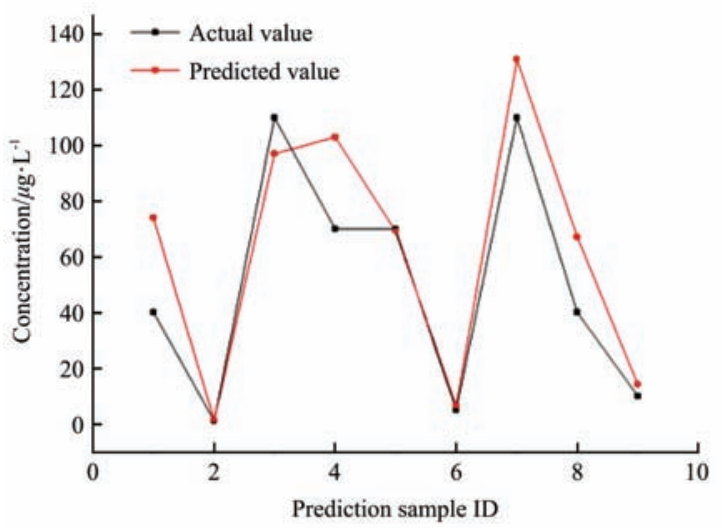

a

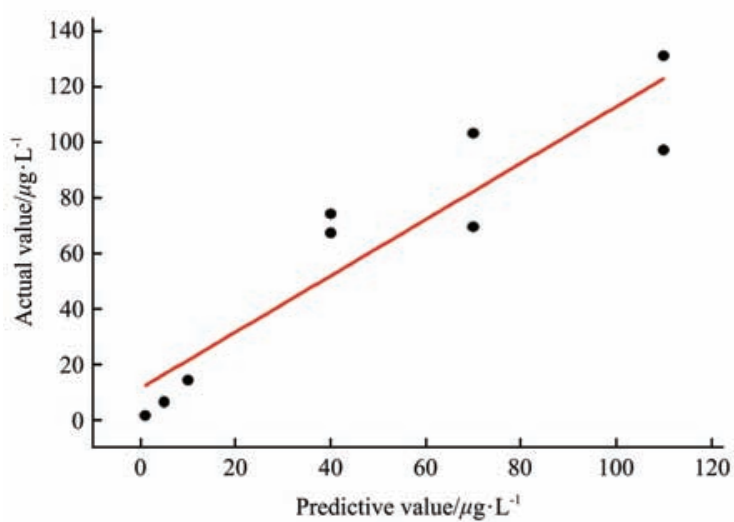

high because of the reasonable MAE, RMSE and $R^{2}$ values for both the training dataset and testing dataset, as shown in Table 2.

Table 2 Prediction results of ANN model on the training dataset and testing dataset

\begin{tabular}{cccc}
\hline Data set & $\mathrm{MAE} / \mu \mathrm{g} \cdot \mathrm{L}^{-1}$ & $\mathrm{RMSE} / \mu \mathrm{g} \cdot \mathrm{L}^{-1}$ & $R^{2}$ \\
\hline Training set & 0.516 & 0.718 & 0.999 \\
Testing set & 1.63 & 1.68 & 0.998 \\
\hline
\end{tabular}

In order to further validate the prediction accuracy of the proposed PSO-SVM model, the prediction results of both the well-trained PSO-SVM model and the direct calibration model with respect to the testing dataset were compared with the actual values, as shown in Figure 6a and Figure 6b. As can be seen in the Figure $6 \mathrm{c}$ and Figure $6 \mathrm{~d}$, the linear regression analysis results indicate that the correlation $\left(R^{2}=0.998\right)$ between the predicted values from the PSO-SVM model and the actual values is strong as compared with the direct calibration model $\left(R^{2}=0.843\right)$.

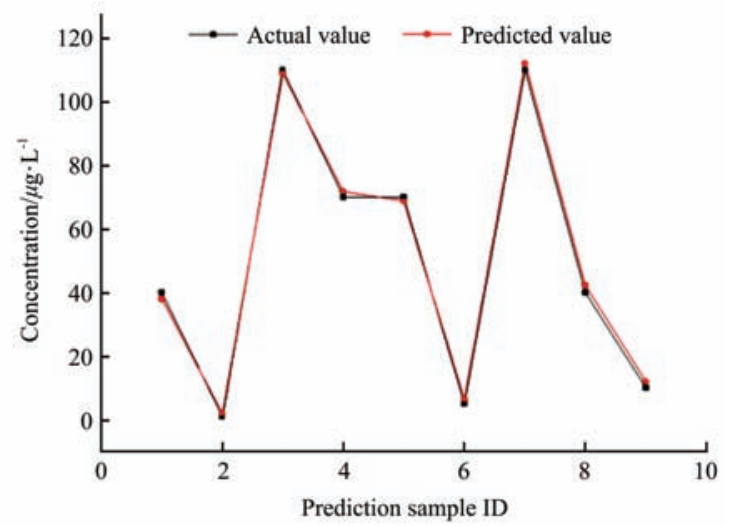

b

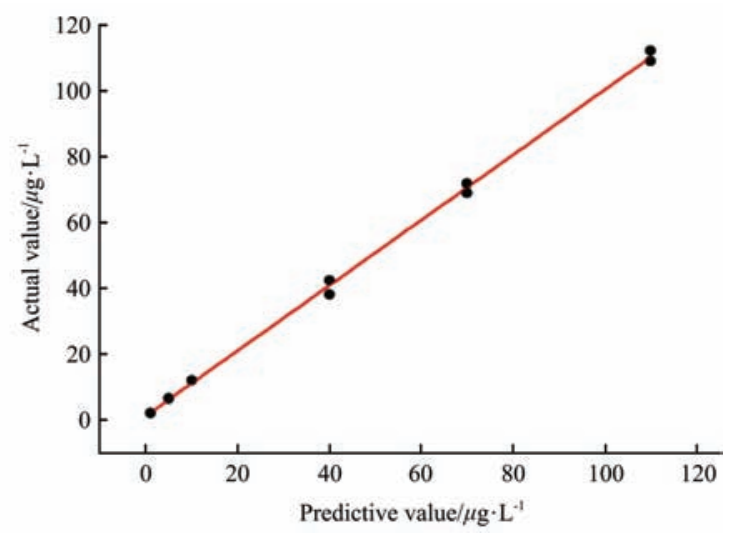

Figure 6 Comparison of prediction results between the (a) direct calibration model and (b) improved PSO-SVM model.

Linear regression analysis of the prediction results obtained from the (c) direct calibration model and (d) improved PSO-SVM model

The generalization ability of the developed PSO-SVM model was evaluated by comparing the statistical parameters (MAE, RMSE and $R^{2}$ ) from the PSO-SVM and from the direct calibration model, both of which were 
used for the prediction of the testing dataset, as shown in

Table 3. Under the optimized conditions, the further statistical analysis results indicate that the improved PSO-SVM model has better prediction precision for the concentration of $\mathrm{Cd}(\mathrm{II})$ than the direct calibration model (MAE and RMSE are $1.63 \mu \mathrm{g} / \mathrm{L}$ and $1.68 \mu \mathrm{g} / \mathrm{L}$ for the improved PSO-SVM model, respectively, and $14.95 \mu \mathrm{g} / \mathrm{L}$ and $20.01 \mu \mathrm{g} / \mathrm{L}$ for the direct calibration model, respectively). This means that the presence of $\mathrm{Pb}$ (II) would make a negative influence on the accuracy of the direct calibration model for the prediction of $\mathrm{Cd}(\mathrm{II})$ concentration.

Table 3 Comparison of prediction results of the direct calibration and PSO-SVM models

\begin{tabular}{cccc}
\hline Prediction method & $\mathrm{MAE} / \mu \mathrm{g} \cdot \mathrm{L}^{-1}$ & $\mathrm{RMSE} / \mu \mathrm{g} \cdot \mathrm{L}^{-1}$ & $R^{2}$ \\
\hline Direct calibration & 14.9 & 20.0 & 0.843 \\
PSO-SVM & 1.63 & 1.68 & 0.998 \\
\hline
\end{tabular}

\subsection{Application to real sample analysis}

To evaluate the applicability of the presented method, the proposed method was applied to the concrete analysis of $\mathrm{Cd}(\mathrm{II})$ in real soil samples. The soil samples were prepared according to Section 2.5, and the experiments were performed by the standard addition method. To improve the stripping peak signals of $\mathrm{Cd}(\mathrm{II})$ and $\mathrm{Pb}(\mathrm{II})$ and eliminate the $\mathrm{Cu}(\mathrm{II})$ interference in $\mathrm{ASV}$, ferrocyanide ions were commonly added to the sample solution $^{[29]}$. Our experiment results show that $0.1 \mathrm{mM}$ ferrocyanide is the effective masking agent, which could mask copper effectively without having a detrimental effect on the $\mathrm{Pb}(\mathrm{II})$ and $\mathrm{Cd}(\mathrm{II})$ responses. Table 4 shows the results obtained from the analysis of the real samples by the proposed method. Satisfactory recovery results were obtained with an average recovery of $98.56 \%$, confirming the availability of the developed method.

Table 4 Results of $\mathrm{Pb}(\mathrm{II})$ detection in soil sample extracts

\begin{tabular}{ccccc}
\hline Sample No. & Added $/ \mu \mathrm{g} \cdot \mathrm{L}^{-1}$ & Found $/ \mu \mathrm{g} \cdot \mathrm{L}^{-1}$ & RSD & Recovery $\%$ \\
\hline \multirow{2}{*}{1} & - & $5.56^{\mathrm{a}}$ & 0.32 & - \\
& 4 & 9.41 & 0.26 & 96.25 \\
& 8 & 13.45 & 0.19 & 98.625 \\
\hline \multirow{2}{*}{2} & - & 6.82 & 0.13 & - \\
& 15 & 21.83 & 0.29 & 100.07 \\
& 30 & 36.37 & 0.14 & 98.50 \\
\hline \multirow{2}{*}{3} & - & 4.94 & 0.28 & - \\
& 45 & 49.19 & 0.21 & 98.33 \\
& 90 & 94.57 & 0.17 & 99.59
\end{tabular}

Note: ${ }^{a}$ SWASV measurements were repeated five times $(n=5)$.

\section{Conclusions}

In this paper, a novel method combining the SWASV, PSO-SVM model and Bi/IL/SPE was proposed. The proposed PSO-SVM model has been used to analyze the SWASV spectrum for the design of $\mathrm{Cd}$ (II) concentration estimating mathematical models within the range of concentrations 1-110 $\mu \mathrm{g} / \mathrm{L}$. Moreover, a disposable $\mathrm{Bi} / \mathrm{IL} / \mathrm{SPE}$ was fabricated and further used for sensitive detection of $\mathrm{Cd}(\mathrm{II})$, which exhibited some advantages over traditional electrodes, such as large surface area, high ionic and electronic conductivity and good sensitivity. To the best of our knowledge, this is the first report of the combination of SWASV and an improved PSO-SVM model using Bi/IL/SPE to predict the concentration of $\mathrm{Cd}(\mathrm{II})$ in the presence of $\mathrm{Pb}(\mathrm{II})$. The statistical analysis results obtained are reasonable for both the training dataset and the testing dataset, which indicates that the improved PSO-SVM model has better prediction precision than the direct calibration model. The feasibility of the proposed method was further confirmed by the real samples analysis with satisfactory recovery results, which holds great promise for its wide application in environmental and food analysis.

\section{Acknowledgements}

This work was financially supported by General Program of National Natural Science Foundation of China (Grant No. 31671578) and National High Technology Research and Development Program of China (Grant No. 2013AA102302).

\section{[References]}

[1] Nriagu J O, Pacyna J M. Quantitative assessment of worldwide contamination of air, water and soils by trace metals. Nature, 1988; 333: 134-139.

[2] Salazar M J, Rodriguez J H, Nieto G L, Pignata M L. Effects of heavy metal concentrations $(\mathrm{Cd}, \mathrm{Zn}$ and $\mathrm{Pb})$ in agricultural soils near different emission sources on quality, accumulation and food safety in soybean (Glycine max L. Merrill). Journal of hazardous materials, 2012; 233: 244-253.

[3] Gao X, Wei W, Yang L, Yin T, Wang Y. Simultaneous determination of lead, copper, and mercury free from macromolecule contaminants by square wave stripping 
voltammetry. Analytical letters, 2005; 38: 2327-2343.

[4] Chamjangali M A, Kouhestani H, Masdarolomoor F, Daneshinejad H. A voltammetric sensor based on the glassy carbon electrode modified with multi-walled carbon nanotube/poly (pyrocatechol violet)/bismuth film for determination of cadmium and lead as environmental pollutants. Sensors and Actuators B: Chemical, 2015; 216 : 384-393.

[5] Zhou W, Li C, Sun C, Yang X. Simultaneously determination of trace $\mathrm{Cd}^{2+}$ and $\mathrm{Pb}^{2+}$ based on 1-cysteine/graphene modified glassy carbon electrode. Food chemistry, 2016; 192: 351-357.

[6] Zhao L, Zhong S, Fang K, Qian Z, Chen J. Determination of cadmium (II), cobalt (II), nickel (II), lead (II), zinc (II), and copper (II) in water samples using dual-cloud point extraction and inductively coupled plasma emission spectrometry. Journal of Hazardous Materials, 2012; 239: 206-212.

[7] Cornard J P, Caudron A, Merlin J C. UV-visible and synchronous fluorescence spectroscopic investigations of the complexation of $\mathrm{Al}$ (III) with caffeic acid, in aqueous low acidic medium. Polyhedron, 2006; 25: 2215-2222.

[8] Guzmán-Mar J L, Hinojosa-Reyes L, Serra A M, Hernández-Ramírez A, Cerdà V. Applicability of multisyringe chromatography coupled to cold-vapor atomic fluorescence spectrometry for mercury speciation analysis. Analytica Chimica Acta, 2011; 708(1-2): 11-18.

[9] Ma Y, Liu H, Qian K, Yang L, Liu J. A displacement principle for mercury detection by optical waveguide and surface enhanced Raman spectroscopy. Journal of Colloid and Interface Science, 2012; 386: 451-455.

[10] Arpadjan S, Celik G, Taşkesen S, Güçer Ş. Arsenic, cadmium and lead in medicinal herbs and their fractionation. Food and Chemical Toxicology, 2008; 46: 2871-2875.

[11] Bagheri H, Afkhami A, Saber-Tehrani M, Khoshsafar H. Preparation and characterization of magnetic nanocomposite of Schiff base/silica/magnetite as a preconcentration phase for the trace determination of heavy metal ions in water, food and biological samples using atomic absorption spectrometry. Talanta, 2012; 97: 87-95.

[12] Zeng W, Chen Y, Cui H, Wu F, Zhu Y, Fritz J S. Single-column method of ion chromatography for the determination of common cations and some transition metals. Journal of Chromatography A, 2006; 1118: 68-72.

[13] Zhou Y, Wang S, Zhang K, Jiang X. Visual detection of copper (II) by azide- and alkyne-functionalized gold nanoparticles using click chemistry. Angewandte Chemie, 2008; 47(39): 7454-7456.

[14] Lin H, Li M, Mihailovič D. Simultaneous determination of copper, lead, and cadmium ions at a Mo6S9-xIx nanowires modified glassy carbon electrode using differential pulse anodic stripping voltammetry. Electrochimica Acta, 2015;
154: 184-189.

[15] Wang Z, Lee P M, Liu E. Graphene thin film electrodes synthesized by thermally treating co-sputtered nickel-carbon mixed layers for detection of trace lead, cadmium and copper ions in acetate buffer solutions. Thin Solid Films, 2013; 544: 341-347.

[16] Mafa P J, Idris A O, Mabuba N, Arotiba O A. Electrochemical co-detection of $\mathrm{As}$ (III), $\mathrm{Hg}$ (II) and $\mathrm{Pb}$ (II) on a bismuth modified exfoliated graphite electrode. Talanta, 2016; 153: 99-106

[17] Lee S, Bong S, Ha J, Kwak M, Park S K, Piao Y. Electrochemical deposition of bismuth on activated graphene-nafion composite for anodic stripping voltammetric determination of trace heavy metals. Sensors and Actuators B: Chemical, 2015; 215: 62-69.

[18] Xiao L, Xu H, Zhou S, Song T, Wang H, Yuan Q, et al. Simultaneous detection of $\mathrm{Cd}$ (II) and $\mathrm{Pb}$ (II) by differential pulse anodic stripping voltammetry at a nitrogen-doped microporous carbon/Nafion/bismuth-film electrode. Electrochimica Acta, 2014; 143: 143-151.

[19] Švancara I, Prior C, Hočevar S B, Wang J. A decade with bismuth-based electrodes in electroanalysis. Electroanalysis, 2010; 22: 1405-1420.

[20] Chen L, Su Z, He X, Liu Y, Qin C, Zhou Y, et al. Square wave anodic stripping voltammetric determination of $\mathrm{Cd}$ and $\mathrm{Pb}$ ions at a $\mathrm{Bi} / \mathrm{Nafion} /$ thiolated polyaniline/glassy carbon electrode. Electrochemistry Communications, 2012; 15: 34-37.

[21] Wang J, Lu J, Kirgöz Ü A, Hocevar S B, Ogorevc B. Insights into the anodic stripping voltammetric behavior of bismuth film electrodes. Analytica Chimica Acta, 2001; 434: 29-34.

[22] María-Hormigos R, Gismera M J, Procopio J R, Sevilla M T. Disposable screen-printed electrode modified with bismuth-PSS composites as high sensitive sensor for cadmium and lead determination. Journal of Electroanalytical Chemistry, 2016; 767: 114-122.

[23] Somé I T, Sakira A K, Mertens D, Ronkart S N, Kauffmann J M. Determination of groundwater mercury (II) content using a disposable gold modified screen printed carbon electrode. Talanta, 2016; 152: 335-340.

[24] Rojas-Romo C, Serrano N, Ariño C, Arancibia V, Díaz-Cruz J. M, Esteban M. Determination of Sb (III) using an ex-situ bismuth screen-printed carbon electrode by adsorptive stripping voltammetry. Talanta, 2016; 155: 21-27.

[25] Clark, A C, Nikolaos K, Barril C, Schmidtke L M, Scollary G R. Measurement of labile copper in wine by medium exchange stripping potentiometry utilising screen printed carbon electrodes. Talanta, 2016; 154: 431-437.

[26] Wei H, Sun J J, Xie Y, Lin C G, Wang Y M, Yin W H, et al. Enhanced electrochemical performance at screen-printed carbon electrodes by a new pretreating procedure. Analytica Chimica Acta, 2007; 588: 297-303. 
[27] Wang J, Lu J, Kirgöz Ü A, Hocevar S B, Ogorevc B. Insights into the anodic stripping voltammetric behavior of bismuth film electrodes. Analytica Chimica Acta, 2001; 434, 29-34.

[28] Sosa V, Barceló C, Serrano N, Ariño C, Díaz-Cruz J M, Esteban M. Antimony film screen-printed carbon electrode for stripping analysis of $\mathrm{Cd}$ (II), $\mathrm{Pb}$ (II), and $\mathrm{Cu}$ (II) in natural samples. Analytica Chimica Acta, 2015; 855: 34-40.

[29] Zhao G, Wang H, Liu G. Electrochemical determination of trace cadmium in soil by a bismuth film/graphene-betacyclodextrin-nafion composite modified electrode. International Journal of Electrochemical Science, 2016; 11: $1840-1851$.

[30] Zhu L, Xu L, Huang B, Jia N, Tan L, Yao S. Simultaneous determination of $\mathrm{Cd}$ (II) and $\mathrm{Pb}$ (II) using square wave anodic stripping voltammetry at a gold nanoparticlegraphene-cysteine composite modified bismuth film electrode. Electrochimica Acta, 2014; 115: 471-477.

[31] Voyant C, Notton G, Kalogirou S, Niveta M-L, Paoli C, Mottea F, et al. Machine learning methods for solar radiation forecasting: A review. Renewable Energy, 2017; 105: 569-582.

[32] Zhao G, Wang H, Liu G, Wang Z Q. Optimization of stripping voltammetric sensor by a back propagation artificial neural network for the accurate determination of $\mathrm{Pb}$ (II) in the presence of Cd (II). Sensors, 2016; 16: 1540-1554.

[33] Yuan J, Yu S, Gao S, Gan Y, Zhang Y, Zhang T, et al. Predicting the biological activities of triazole derivatives as SGLT2 inhibitors using multilayer perceptron neural network, support vector machine, and projection pursuit regression models. Chemometrics and Intelligent Laboratory Systems, 2016; 156: 166-173.

[34] Huang C L, Dun J F. A distributed PSO-SVM hybrid system with feature selection and parameter optimization. Applied Soft Computing, 2008; 8: 1381-1391.

[35] Yang H C, Zhang S B, Deng K Z, Du P J. Research into a feature selection method for hyperspectral imagery using PSO and SVM. Journal of China University of Mining and Technology, 2007; 17: 473-478.

[36] Chen B T, Chen M Y. Applying particles swarm optimization for support vector machines on predicting company financial crisis. International Proceedings of Economics Development and Research, 2010; 1: 301-305.

[37] Zhai Y J, Li H L, Zhou Q. Research on SVM algorithm with particle swarm optimization. Proceedings of the 11th Joint Conference on Information Sciences, 2008.

[38] Zhang, X., and Guo, Y. Optimization of SVM parameters based on PSO algorithm. Proceedings of the 2009 Fifth International Conference on Natural Computation (ICNC 2009), 2009; 1: 536-539.

[39] Subasi A. Classification of EMG signals using PSO optimized SVM for diagnosis of neuromuscular disorders.
Computers in Biology and Medicine, 2013; 43: 576-586.

[40] Bao Y, Hu Z, Xiong T. A PSO and pattern search based memetic algorithm for SVMs parameters optimization. Neurocomputing, 2013; 117: 98-106.

[41] Ardjani F, Sadouni K, Benyettou M. Optimization of SVM multiclass by particle swarm (PSO-SVM). 2010 2nd International Workshop on Database Technology and Applications Proceedings(DBTA), 2010; 1: 1-4.

[42] Yang Q, Zou H Y, Zhang Y, Tang L J, Shen G L, Jiang J H, et al. Multiplex protein pattern unmixing using a non-linear variable-weighted support vector machine as optimized by a particle swarm optimization algorithm. Talanta, 2016; 147: 609-614.

[43] Singh K P, Basant N, Gupta S. Support vector machines in water quality management. Analytica Chimica Acta, 2011; 703: $152-162$.

[44] Wang G, Ma M, Zhang Z, Xiang Y, Harrington P D B. A novel DPSO-SVM system for variable interval selection of endometrial tissue sections by near infrared spectroscopy. Talanta, 2013; 112: 136-142.

[45] Cao D S, Liu S, Fan L, Liang Y Z. QSAR analysis of the effects of OATP1B1 transporter by structurally diverse natural products using a particle swarm optimizationcombined multiple linear regression approach. Chemometrics and Intelligent Laboratory Systems, 2014; 130: 84-90.

[46] Xing J J, Liu Y F, Li Y Q, Gong H, Zhou Y P. QSAR classification model for diverse series of antimicrobial agents using classification tree configured by modified particle swarm optimization. Chemometrics and Intelligent Laboratory Systems, 2014; 137: 82-90.

[47] Lou I, Xie Z, Ung W K, Mok K M. Integrating support vector regression with particle swarm optimization for numerical modeling for algal blooms of freshwater. Applied Mathematical Modelling, 2015; 39: 5907-5916.

[48] Liu B, Lu L, Wang M, Zi Y. A study of nafion-coated bismuth-film electrode for the determination of zinc, lead, and cadmium in blood samples. Electroanalysis, 2008; 20: 2363-2369.

[49] Ren R, Leng C, Zhang S. A chronocoulometric DNA sensor based on screen-printed electrode doped with ionic liquid and polyaniline nanotubes. Biosensors and Bioelectronics, 2010; 25: 2089-2094.

[50] Li Y, Liu X, Zeng X, Liu Y, Liu X, Wei W, et al. Simultaneous determination of ultra-trace lead and cadmium at a hydroxyapatite-modified carbon ionic liquid electrode by square-wave stripping voltammetry. Sensors and Actuators B: Chemical, 2009; 139: 604-610.

[51] Lee S, Bong S, Ha J, Kwak M, Park S K, Piao Y. Electrochemical deposition of bismuth on activated graphene-nafion composite for anodic stripping voltammetric determination of trace heavy metals. Sensors and Actuators B: Chemical, 2015; 215: 62-69. 